\title{
The Effect of Tamsulosin on Stone Free Rate after SWL: A Placebo Controlled Study
}

\author{
TARIK OSMAN, M.D.; KARIM OMAR, M.D. and AHMED SAMY, M.Sc. \\ The Department of Urology, Faculty of Medicine, Ain Shams University
}

\begin{abstract}
Background: Extracorporeal Shock Wave Lithotripsy (ESWL) is a noninvasive technique for the treatment of kidney stones. Most ESWL is carried out when the stone is present in the renal pelvis.

Aim of Study: To evaluate the efficacy of alpha blocker (tamsulosin) to enhance stone fragments clearance from urinary tract after ESWL on renal pelvic stones.

Methods: This is prospective randomized study which was carried out at Urology Department Ain Shams University Hospital during the period from August 2017 till July 2018 After hospital ethical committee approval, a total of 56 patients fulfilling inclusion criteria with symptomatic single renal pelvic radiopaque stone $\leq 1 \mathrm{~cm}$ were included in this study. All patients underwent ESWL therapy for their stone. Patients were randomized into two groups; group A (received tamsulosin $0.4 \mathrm{mg}$ ) and group B (received placebo).
\end{abstract}

Results: After two weeks of follow up PUT was done and revealed post ESWL SFR (stone free rate) on placebo group was $86.9 \%$ and SFR on tamsulosin group was $92.5 \%$ ( $p$ value $=0.2$ ) (no statistically significant difference) on the other hand post ESWL pain was significantly more among group B (placebo group) of 73.9\% compared to group A (tamsulosin group) of $3.7 \%$ ( $p$-value $=0.0023$ ), and Dizziness in tamsulosin group was $18.5 \%$ of the group patients experienced it while none of the placebo group complained of that, $(p$-value $=$ $0.003)$.

Conclusion: When the stones were $(\leq 10 \mathrm{~mm}$, no improvement was seen in the success rates by adding Medical Expulsive Therapy (MET) in the form of alpha blocker than placebo, as has been reported in other studies, but post ESWL pain is less with adding tamsulosin.

Key Words: ESWL-Renal stone - Alpha blocker.

\section{Introduction}

ESWL involves the use of a lithotriptor machine to deliver externally applied, focused, high-intensity

Correspondence to: Dr. Ahmed Samy, E-Mail: dr.ahmedsamy88@yahoo.com pulses of shock waves to cause fragmentation of a stone over a period of around 30-60 minutes.

It is agreed that the preferred approach for stones $<1 \mathrm{~cm}$ is ESWL, whereas for stones $>2 \mathrm{~cm}$ is PNL. However, the management of stones of $1-2 \mathrm{~cm}$ is still controversial [1]. The most important factors that affect the outcome of ESWL are stone burden and stone location. Various studies have concluded that the results of ESWL are satisfactory if the size of stone is $<2 \mathrm{~cm}$, especially in non lower pole location $[2,3]$. The highest clearance is achieved with calculi in the renal pelvis and at the pelviureteric junction [4]

In one study, the stone free rate for stones in the renal pelvis, lower, middle, and upper calices were $72.4,56,55.6$, and $69 \%$, respectively, whereas that for stones $1 \mathrm{~cm}, 1.1$ to $2 \mathrm{~cm}$, and $>2 \mathrm{~cm}$ were $50.2,39.6$, and $10.2 \%$ respectively [4] .

The use of medications to speed the spontaneous passage of stones in the ureter is referred as medical expulsive therapy [5]. Several agents, including alpha adrenergic blockers (such as tamsulosin) and calcium channel blockers (such as nifedipine), have been found to be effective [5]. Alpha blockers appear to lead to higher and faster stone clearance rates, and they are mostly effective for stones over $4 \mathrm{~mm}$ and less than $10 \mathrm{~mm}$ in size [6]

Adding medication to ESWL has been suggested to improve the success rate such as tamsulosin (alpha blocker) and nifedipine (calcium channel blocker) [6]

\section{Aim of the study:}

To evaluate the efficacy of alpha blocker (tamsulosin) to enhance stone fragments clearance from urinary tract after ESWL on renal pelvic stones 
and increased stone free rate after ESWL compared to placebo.

\section{Patients and Methods}

This is a prospective placebo-controlled, randomized, double-blind clinical trial carried out at Urology Department, Ain Shams University Hospital during the period from August 2017 till July 2018. After hospital ethical committee approval, a total of 56 patients fulfilling inclusion criteria with symptomatic single renal pelvic radiopaque stone $(<1) \mathrm{cm}$ were included in this study. These patients underwent (ESWL) therapy as primary stone management.

Complete history taking, physical examination and routine laboratory and radiological investigations were performed for each patient.

\section{Inclusion criteria:}

Patients with symptomatic single renal pelvic radiopaque stone $(<1) \mathrm{cm}$ indicated for ESWL were included in the study.

\section{Exclusion criteria:}

Patients with one or more of the following were excluded from the study: Urinary tract infection, uncorrected bleeding coagulopathy, congenital anomalies of the urinary tract, past history of urinary tract surgery, aged less than 18 or more than 65 years old, pregnant female, high body mass index (more than 35), multiple renal stones, calyceal stones, previous unsuccessful ESWL, severe vertebral malformations or associated with aortic aneurysm, distal ureteric obstruction and or hypersensitivity to tamsulosin $0.4 \mathrm{mg}$.

\section{Patient evaluation:}

All patients included in the study were fully examined after full history taking and then: Laboratory tests were performed including urine analysis, prothrombin time $\&$ activity and INR, blood urea and creatinine, liver function tests, CBC. Imaging studies comprised of P.U.T (plain X-ray on urinary tract), Pelviabdominal ultrasound, and non enhanced CTUT (computed tomography of urinary tract).

Patients fulfilled the inclusion and exclusion criteria were subjected to stone ESWL; the machine used was Dornier compact equipped with an electromagnetic shock wave source (EMSE 140), (of frequency of 3000 waves and intensity of $15 \mathrm{k} . \mathrm{v}$ ) fixed for all patients, fluoroscopic imaging system with $\mathrm{C}$ arm used to localize the stone for focusing the shock wave. During the procedure intravenous Nalufin was used as pain killer.

After ESWL, randomization was performed using a computer random number generator. The patients were randomized into placebo (28 patients) or tamsulosin $0.4 \mathrm{mg}$ ( 28 patients) groups. Both patients and physician were blinded regarding the treatment.

\section{Follow-up:}

Patients were followed-up for two weeks. During which treatment was given (either tamsulosin or placebo) \& Diclophenac sodium was advised for analgesia on demand. The patients were instructed to drink $3 \mathrm{~L}$ of liquid daily and to sieve their urine to document stone expulsion. The following were noted stone elimination, renal colic, pain severity, the use of analgesics, emergency visits, blood pressure changes, and adverse drug events.

Patients returned two weeks later for followup examinations \& digital abdominal plain radiography was performed. The parameters studied for stone clearance, the number of Diclophenac sodium tablets used, the pain intensity (as determined by a numerical pain scale), adverse drug events, and emergency visits. Of total 56 patients enrolled in the study 6 patients did not return for follow-up and were excluded from the analysis.

ESWL success (stone free) was defined as complete elimination of the stone or the presence of clinically asymptomatic residual fragments in the kidney of $<4 \mathrm{~mm}$ at 2 weeks.

\section{Statistical analysis:}

Data were collected, revised, coded and input into the Statistical Package for Social Science (IBM SPSS) Version 20 and the following were done: Qualitative data were presented as number and percentages while quantitative data were presented as mean, standard deviations and ranges. The comparison between two groups with qualitative data were done by using Chi-square test. The comparison between two independent groups with quantitative data and parametric distribution was done by using independent $t$-test. The confidence interval was set to $95 \%$ and the margin of error accepted was set to $5 \%$.

\section{Results}

Both groups were comparable in their baseline demographic aspects. There was no statistically significant difference between the 2 groups with regard to location of stone, their sex, and age. 
Regarding post ESWL analgesic requirements, we defined analgesic requirement according to number of diclophenac sodium tablets the patients used (less than 5 tablets (mild), 5-10 tablets (moderate), more than 10 tablets (severe). Only 1 patient in tamsulosin group (3.7\%) required more than 10 tablets compared to 6 patients in placebo group $(26.1 \%),(p$-value $=0.023)$ statistically significant difference between both groups.

Moreover, post ESWL pain regarding numerical scale, the median was in placebo group, but was in tamsulosin group.

On the other hand, 5 patients $(18.5 \%)$ of tamsulosin group experienced dizziness and postural hypotension following ESWL and none of the control group had such complaint, $(p$-value $=0.030)$ with statistically significant difference between the two groups.

The overall stone clearance rate was $86.9 \%$ (20 patients) in placebo group and $92.5 \%$ (25 patients) in the tamsulosin group; and the difference was not statistically significant $(p$-value $=0.20)$.

Table (1): Show age of the patients involved in our study.

\begin{tabular}{lllllll}
\hline & \multicolumn{2}{c}{ Age (years) } & & \multicolumn{2}{c}{$t$-test } \\
\cline { 2 - 3 } \cline { 5 - 6 } & Range & Mean \pm SD & & \multicolumn{2}{c}{$t$} & D-value \\
\hline Placebo & $20-43$ & $32.57 \pm 4.15$ & & 1.383 & 0.173 \\
Tamsulosin $(0.4 \mathrm{mg})$ & $21-45$ & $34.09 \pm 3.62$ & & \\
\hline
\end{tabular}

Table (2): Show sex distribution between both groups in our study.

\begin{tabular}{|c|c|c|c|c|c|c|}
\hline \multirow{2}{*}{ Sex } & \multicolumn{2}{|c|}{ Placebo } & \multicolumn{2}{|c|}{ Tamsulosin $(0.4 \mathrm{mg})$} & \multicolumn{2}{|c|}{ Total } \\
\hline & $\mathrm{N}$ & $\%$ & $\mathrm{~N}$ & $\%$ & $\mathrm{~N}$ & $\%$ \\
\hline Male & 9 & 39.1 & 12 & 44.4 & 21 & 42.0 \\
\hline Female & 14 & 60.9 & 15 & 55.6 & 29 & 58.0 \\
\hline Total & 23 & 100.0 & 27 & 100.0 & 50 & 100.0 \\
\hline $\begin{array}{c}\text { Chi-square: } \\
\chi^{2} \\
p \text {-value }\end{array}$ & & & & & & \\
\hline
\end{tabular}

Table (3): Shows the post ESWL pain and analgesic requirement of the two groups in the study.

\begin{tabular}{lllllll}
\hline \multirow{2}{*}{$\begin{array}{l}\text { Post ESWL } \\
\text { pain }\end{array}$} & \multicolumn{2}{c}{ Placebo } & \multicolumn{2}{c}{ Tamsulosin $(0.4 \mathrm{mg})$} & \multicolumn{2}{c}{ Total } \\
\cline { 2 - 7 } & $\mathrm{N}$ & $\%$ & $\mathrm{~N}$ & $\%$ & $\mathrm{~N}$ & $\%$ \\
\hline Group B & 6 & 26.1 & 1 & 3.7 & 7 & 14.0 \\
Group A & 17 & 73.9 & 26 & 96.3 & 43 & 86.0 \\
Total & 23 & 100.0 & 27 & 100.0 & 50 & 100.0 \\
Chi-square: & & \multicolumn{3}{c}{5.168} & & \\
$\quad \chi^{2}$ & & \multicolumn{3}{c}{$0.023 *$} \\
$p$-value & & \multicolumn{5}{c}{} \\
\hline
\end{tabular}

Table (4): Show patients experienced dizziness and postural hypotension during study.

\begin{tabular}{lllllll}
\hline \multirow{2}{*}{ Dizziness } & \multicolumn{3}{c}{ Placebo } & \multicolumn{2}{c}{ Tamsulosin $(0.4 \mathrm{mg})$} & \multicolumn{2}{c}{ Total } \\
\cline { 2 - 7 } & $\mathrm{N}$ & $\%$ & $\mathrm{~N}$ & $\%$ & $\mathrm{~N}$ & $\%$ \\
\hline Yes & 0 & 0.0 & 5 & 18.5 & 5 & 10.0 \\
No & 23 & 100.0 & 22 & 81.5 & 45 & 90.0 \\
Total & 23 & 100.0 & 27 & 100.0 & 50 & 100.0 \\
Chi-square: & \multicolumn{5}{c}{4.733} \\
$\quad{ }^{2}$ & \multicolumn{5}{c}{$0.030^{*}$} \\
$p$-value & \multicolumn{9}{c}{} \\
\hline
\end{tabular}

Table (5): Shows the post ESWL stone free rate in both groups of the study.

\begin{tabular}{lllcccc}
\hline \multirow{2}{*}{$\begin{array}{l}\text { Stone free } \\
\text { rate }\end{array}$} & \multicolumn{2}{c}{ Placebo } & \multicolumn{2}{c}{ Tamsulosin $(0.4 \mathrm{mg})$} & \multicolumn{2}{c}{ Total } \\
\cline { 2 - 7 } & $\mathrm{N}$ & $\%$ & $\mathrm{~N}$ & $\%$ & $\mathrm{~N}$ & $\%$ \\
\hline Yes & 20 & 86.9 & 25 & 92.5 & 45 & 90 \\
No & 3 & 13.1 & 2 & 7.5 & 5 & 10 \\
Total & 23 & 100.0 & 27 & 100.0 & 50 & 100.0 \\
Chi-square: & \multicolumn{5}{c}{0.3608} \\
$\quad \chi^{2}$ & \multicolumn{5}{c}{0.2} \\
$p$-value & \multicolumn{9}{c}{} \\
\hline
\end{tabular}

\section{Discussion}

In our study to evaluate efficacy of alpha blocker on post ESWL stone clearance, no statistically significant value of tamsulosin over placebo was found. However,tamsulosin decreased post ESWL pain and analgesics requirements.

Our results are comparable to the results reported by Bhagat and his colleagues [9], Gravina and his colleagues [8], Nunzio and his colleagues [12] and Falahatkar and colleagues [13]. All studies stated that there was no significant difference between tamsulosin and control groups regarding renal stones ranging $6-10 \mathrm{~mm}$.

Moreover, in a randomised non placebo controlled study, it was found that tamsulosin enhanced post ESWL stone clearance when size was 11-20 $\mathrm{mm}$ [8]. Yet no effect of tamsulosin if the stone size $\leq 10 \mathrm{~mm}$; this later finding is similar to our study result. Gravina reported also tamsulosin decreased post ESWL pain and analgesic requirement, similar to our study [8].

2 randomized placebo controlled double blinded studies, reported that stone free rates after ESWL with adjuvant tamsulosin or nifedipine or Alfuzosin $[10,11]$ were significantly increased only for non lower pole renal stones $10-20 \mathrm{~mm}$ in size compared with placebo.

In contrast to these later studies, our study showed no significant value of Tamsulosin for post 
ESWL stone clearance. This may be contributed to the strict inclusion criteria of our patient and to the fixed ESWL protocol we followed.

\section{Conclusion:}

Alpha blocker (tamsulosin)showed no value as adjunctive therapy to ESWL for clearance of renal pelvic stone $\leq 10 \mathrm{~mm}$, on the other hand it significantly reduced post ESWL pain and analgesic requirements.

\section{References}

1- SEITZ C., LIATSIKOS E., PORPIGLIA F., TISELIUS H.G., et al.: "Medical Therapy To Facilitate The Passage Of Stones: What Is The Evidence?". European Urology September, 56 (3): 455-71, 2009.

2- CAMPSCHROER T., ZHU Y., DUIJVESZ D., GROBBEE D.E. and LOCK M.T.: (2 April 2014). "Alpha-Blockers As Medical Expulsive Therapy for Ureteral Stones". The Cochrane Database of Systematic Reviews, 4 (4): CD008509, 2014.

3- WANG RALPH C., SMITH-BINDMAN REBECCA, WHITAKER EVANS, NEILSON JERSEY, ALLEN ISABEL ELAINE, STOLLER MARSHALL L. and FAHIMI JAHAN: "Effect Of Tamsulosin On Stone Passage For Ureteral Stones: A Systematic Review And MetaAnalysis". Annals of Emergency Medicine September, 2016.

4- GALVIN D.J. and PEARLE M.S.: The contemporary management of renal and ureteric calculi. B.J.U. Int., 6: 1283-8, 2006

5- SAXBY M.F., SORAHAN T., SLANEY P. and COPPINGER S.W.: A case-control study of percutaneous nephrolithotomy versus extracorporeal shock wave lithotripsy. Br. J. Urol., 79: 317-23, 1997.

6- RAO P.P., DESAI R.M., SABNIS R.S., PATEL S.H. and DESAI M.R.: The relative cost-effectiveness of PCNL and ESWL for medium sized $(>2 \mathrm{cms})$ renal calculi in a tertiary care urological referral centre. Indian J. Urol., 17: 121-3, 2001.

7- SRIVASTAVA A. and CHIPDE S.S.: Management of 1$2 \mathrm{~cm}$ renal stones. Indian Journal of Urology: IJU: Journal of the Urological Society of India, Jul., 29 (3): 195, 2013.

8- GRAVINA G.L., COSTA A.M., RONCHI P., GALATIOTO G.P., ANGELUCCI A., CASTELLANI D., NARCISI F. and VICENTINI C.: Tamsulosin treatment increases clinical success rate of single extracorporeal shock wave lithotripsy of renal stones. Urology, Jul. 1, 66 (1): 24-8, 2005.

9- BHAGAT S.K., CHACKO N.K., KEKRE N.S., GOPALAKRISHNAN G., ANTONISAMY B. and DEVASIA A.: Is there a role for tamsulosin in shock wave lithotripsy for renal and ureteral calculi? The Journal of Urology, Jun. 1, 177 (6): 2185-8, 2007.

10- PIRZADA A.J., ANWAR A., JAVED A., MEMON I. and MOHAMMAD A.: Role of alpha-1 blocker in expulsion of stone fragments after extracorporeal shock wave lithotripsy for renal stones. Journal of Ayub Medical College Abbottabad, 23 (2): 125-9, 2011.

11- VICENTINI F.C., MAZZUCCHI E., BRITO A.H., NETO E.A., DANILOVIC A. and SROUGI M.: Adjuvant tamsulosin or nifedipine after extracorporeal shock wave lithotripsy for renal stones: A double blind, randomized, placebo-controlled trial. Urology, 78 (5): 1016-21, 2011.

12- NUNZIO C.D., ALDO BRASSETTI, BELLANGINO M., TRUCCHI A., PETTA S., PRESICCE F. and TUBARO A.: Tamsulosin or Silodosin Adjuvant Treatment Is Ineffective in Improving Shockwave Lithotripsy Outcome: A Short-Term Follow-Up Randomized, PlaceboControlled StudyJournal of Endourology Vol. 30, No. 7 , 2016.

13- FALAHATKAR S., KHOSROPANAH I., VAJARY A.D., BATENI Z.H., KHOSROPANAHAN D. and ALLAHKHAH A.: Is There a Role for Tamsulosin After Shock Wave Lithotripsy in the Treatment of Renal and Ureteral Calculi? Journal of Endourology Vol. 25, No. 3, 2011. 


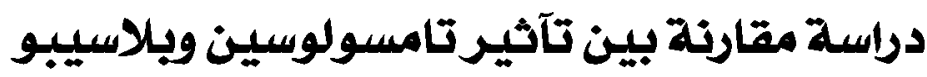

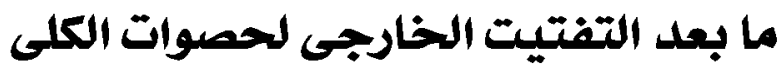

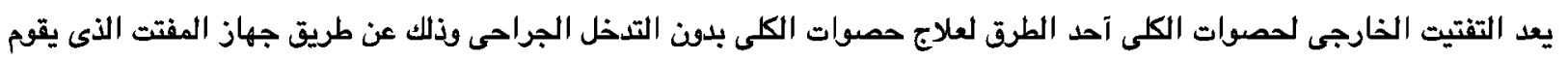

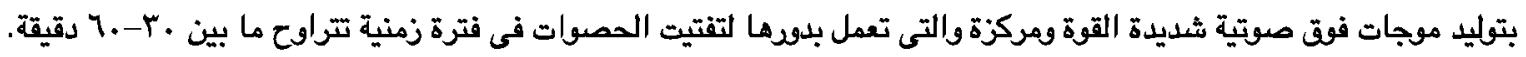
هناك بعض العوامل المساعده للتخلص من بقايا الحصوه ما بعد التفتيت مثل إستخدام آدوية ك الفابلوكر (تامسولوسين) آو نيفيدين والتى

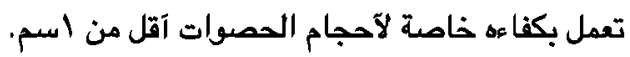
جدير بالذكر آن هناك طرق متعددة اللتخلص من حصوات الكلى بالإضافة إلى التفتيت الخارجى الحصوات مثل منظار الكلى والفتح الجراحى آو عن طريق منظار الحالب المن.

الهدف من دراستتا تقييم مدى كفاءه تامسولوسين فى التخلص من بقايا حصوات حوض الكلى ما بعد التفتيت من المجرى البولى.

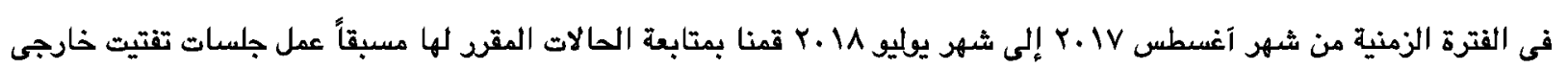

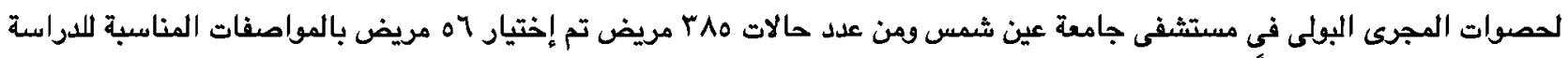

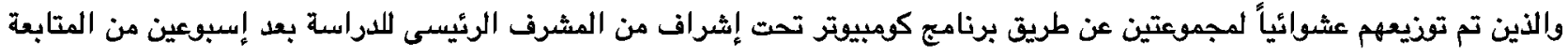
الدوية قمنا بعمل آشعة عادية للمقارنة بين المجموعتين. 